\title{
DIVERSIDADE GENÉTICA ESTIMADA ATRAVÉS DE MARCADORES ISSR DE Colletotrichum graminicola NO BRASIL
}

\author{
DOUGLAS FERREIRA PARREIRA ${ }^{1}$, LAÉRCIO ZAMBOLIM ${ }^{1}$, ELIANE APARECIDA GOMES ${ }^{2}$, \\ RODRIGO VERAS DA COSTA², DAGMA DIONÍSIA DA SILVA ${ }^{2}$, UBIRACI GOMES DE PAULA \\ LANA $^{2}$, WANIA DOS SANTOS NEVES ${ }^{3}$, JOSÉ EDSON FONTES FIGUEIREDO ${ }^{2}$ \\ e LUCIANO VIANA COTA ${ }^{2}$
}

\author{
${ }^{1}$ Universidade Federal de Viçosa, Viçosa, MG, Brasil-douglas2002ufv@yahoo.com.br, zambolim@ufv.br \\ 2Embrapa Milho e Sorgo,Sete Lagoas, MG, Brasil-eliane.a.gomes@embrapa.br, \\ rodrigo.veras@embrapa.br,dagma.silva@embrapa.br,luciano.cota@embrapa.br, \\ ubiraci.lana@embrapa.br,jose.edson@embrapa.br. \\ ${ }^{3}$ Empresa de Pesquisa Agropecuária de Minas Gerais, \\ Unidade Regional EPAMIG Sudeste, Viçosa, MG, Brasil-wanianeves@epamig.br.
}

Revista Brasileira de Milho e Sorgo, v.15, n.2, p. 186-194, 2016

\begin{abstract}
RESUMO - A antracnose do milho causada pelo fungo Colletotrichum graminicola é uma das principais doenças da cultura no Brasil e no mundo, atacando praticamente todas as partes da planta. Neste trabalho, foi avaliada a variabilidade genética de 95 isolados monospóricos de C. graminicola provenientes dos estados de Goiás, Minas Gerais, Santa Catarina, São Paulo, Paraná e Rio Grande do Sul. Foram avaliados 15 primers ISSR, sendo selecionados nove que resultaram em um maior polimorfismo. Os fragmentos de DNA gerados pelas análises de ISSR foram avaliados mediante inspeção visual dos géis. Bandas de mesmo peso molecular, em indivíduos diferentes, foram consideradas idênticas e designadas em função da ausência (0) e presença (1) no gel. Baseado na matriz, foi gerado um dendrograma pelo método UPGMA, utilizando as 66 bandas amplificadas pelos nove primers ISSR. Ao analisar o dendrograma, foi traçada uma linha divisória no valor da distância de dissimilaridade de 0,3 , dividindo os isolados em sete grupos. Baseado nos resultados, foi possível concluir que a variabilidade genética entre os isolados de C. graminicola é alta, sendo os marcadores ISSR eficazes na determinação de sua variabilidade. Os isolados utilizados no presente trabalho não apresentam estruturação geográfica.
\end{abstract}

Palavras-chave: antracnose; milho; UPGMA.

\section{GENETIC DIVERSITY ESTIMATED THROUGH ISSR MARKERS OF Colletotrichum graminicola IN BRAZIL}

\begin{abstract}
The anthracnose of corn caused by the fungus Colletotrichum graminicola is one of main diseases in the world including Brazil, infecting any part of the plant. This study evaluated the genetic variability of 95 monosporic isolates of C. graminicola from the Brazilian states of Goiás, Minas Gerais, Santa Catarina, São Paulo, Paraná and Rio Grande do Sul. Fifteen ISSR primers were evaluated by their DNA fragments through gels visual inspections, considering absence (0) or presence (1) for bands with the same molecular weight in different individuals making a matrix, and 9 primers showed a higher polimorfism. Based on the matrix obtained, a dendogram was generated by the UPGMA method with all 66 bands amplified from these same 9 ISSR primers, separating 7 isolated groups by a dissimilarity distance of 0.3 . The ISSR markers were efficient to determine a high genetic variability between the isolates of $C$. graminicola but it was not possible to group them geographically.
\end{abstract}

Key words: anthracnose; corn; UPGMA.

Versão impressa ISSN 1676-689X / Versão on line ISSN 1980-6477

http://www.rbms.cnpms.embrapa.br 
O gênero Colletotrichum agrupa alguns dos patógenos mais importantes na agricultura, em virtude das perdas potenciais que podem causar, sendo primordial a capacidade de diagnóstico desta doença. No milho, a antracnose causada por $C$. graminicola destaca-se como uma das principais doenças da cultura (Bergstrom \& Nicholson, 1999), uma vez que o patógeno é capaz de infectar praticamente toda a planta. $\mathrm{Na}$ fase foliar, a doença caracteriza-se pela presença de lesões de formas variadas e necróticas, podendo ocorrer extensa queima das folhas. Nas nervuras, é comum a presença de lesões elípticas com acérvulos do patógeno. A fase de podridão de colmo é caracterizada pela formação, na casca, de lesões estreitas e elípticas, as quais tornam-se, posteriormente, marrom escuras a negras, e pela formação de acérvulos do patógeno. Estimativas dos efeitos da antracnose foliar e da podridão de colmo na produção de grãos de milho variam de $0 \%$ a $40 \%$, dependendo da cultivar, das condições ambientais, da época de ocorrência das epidemias e da ocorrência de outras pragas (Cota et al., 2012).

A principal medida de manejo da antracnose do milho é o uso de cultivares resistentes. Para o sucesso do uso da resistência genética e a ampliação da vida útil dos genes de resistência, é importante o conhecimento da diversidade genética da população do patógeno, assim como a correta identificação da espécie ou da raça predominante na população. Algumas variações de ordem taxonômica têm sido resolvidas através do uso de ferramentas moleculares, pois, para este grupo, os critérios taxonômicos geralmente se sobrepõem, tendo ainda algumas espécies uma gama de hospedeiros e, dentre esses hospedeiros, alguns são infectáveis por mais de uma espécie de Colletotrichum (Crouch \& Beirn, 2009; Hyde et al., 2009b). A partir de estudos realizados com espécies de Colletotrichum possuidoras de conídios falcifor- mes, utilizando os genes DNA liase (Apn2), mating type (Mat1), manganês superóxido desmutase (Sod2) e regiões ITS do rDNA (Internal Transcribed Spacer), foi possível separar as espécies levando em conta alguns caracteres taxonômicos como dimensões e tamanho do apressório (Cai et al., 2009; Crouch et al., 2006, 2009b). Outro fator importante é a presença de sequências erroneamente depositadas no GenBank, sendo considerado que, para fungos, mais de $20 \%$ das sequências depositadas podem estar comprometidas (Bidartondo, 2008), o que pode ser remediado nos trabalhos de filogenia com o uso de isolados tipo provenientes de coleções de culturas internacionais (Cai et al., 2009; Crouch et al., 2009a; Hyde et al., 2009a).

$\mathrm{O}$ uso de marcadores moleculares se encontra bem difundido, existindo uma grande demanda quanto aos marcadores baseados nas reações de PCR (Polymerase Chain Reaction) devido à simplicidade e à necessidade de pequenas quantidades de DNA da amostra. Os marcadores ISSR (Inter-Simple Sequence Repeat) são amplificados via PCR e não necessitam do sequenciamento da região, resultando ainda na obtenção de padrões altamente polimórficos com resultados que possuem repetibilidade (Bornet \& Branchard, 2001; Nagaoka \& Ogihara, 1997). Além disso, são dominantes, podendo gerar um grande número de alelos reproduzíveis e altamente polimórficos utilizando um primer complementar a uma região de microssatélite alvo. No trabalho realizado por Nghia et al. (2008), além de marcadores ISSR, foram utilizados outros caracteres como morfologia de colônia e dos conídios nos estudos de isolados de Corynespora cassiicola provenientes de plantios de seringueira (Hevea brasiliensis) na Malásia. Neste estudo, os autores concluíram que apenas os caracteres morfológicos não seriam suficientes para diferenciar os isolados de C. cassiicola. Esses e outros trabalhos 
têm demonstrado o crescente uso destes marcadores sozinhos ou em conjunto com outras ferramentas no estudo da variabilidade dos fungos.

Considerando a inexistência de informações na literatura sobre o uso de marcadores ISSR para o fungo C. graminicola e o potencial do marcador para estudo da diversidade do patógeno, o objetivo deste trabalho foi estimar a diversidade genética de populações de C. graminicola por meio de marcadores moleculares ISSR. Os objetivos específicos foram avaliar o nível de variação de ISSRs entre isolados de C. graminicola provenientes de diferentes regiões e entre o material utilizado para o isolamento quando possível (colmo, folha e nervura).

\section{Material e Métodos}

\section{Obtenção dos isolados monospóricos de Colletotrichum graminicola}

Para obtenção dos isolados monospóricos de $C$. graminicola, fragmentos de colmo, folhas e nervura com sintomas típicos de antracnose provenientes dos estados de Goiás, Minas Gerais, Santa Catarina, São Paulo, Paraná e Rio Grande do Sul foram esterilizados durante 2 min em solução de hipoclorito de sódio a $0,5 \%$ e transferidos para placas de Petri contendo meio de farinha de aveia-ágar-tetraciclina (FAAT) (aveia: $60 \mathrm{~g} / \mathrm{L}$, ágar: $20 \mathrm{~g} / \mathrm{L}$, tetraciclina: $300 \mathrm{mg} / 100$ $\mathrm{ml})$. As placas foram incubadas em condição de luz fluorescente intermitente $\mathrm{a} \pm 25^{\circ} \mathrm{C}$, durante sete a oito dias, para induzir a esporulação. Após a esporulação, os conídios foram colhidos, adicionando-se, aproximadamente, $10 \mathrm{~mL}$ de água estéril em cada placa, seguindo-se uma raspagem superficial para sua liberação.

A partir das suspensões originais, foram realizadas diluições seriais de $10^{-1}$ a $10^{-3}$ para obtenção de suspensões de esporos com a concentração de 50100 conídios/mL. Um mililitro dessa suspensão foi transferido para placas de Petri contendo ágar-água a $2 \%$, sendo mantidas em câmaras de crescimento sob luz fluorescente intermitente a $25{ }^{\circ} \mathrm{C}$ durante 12 h para induzir a germinação dos conídios. Conídios germinados foram retirados individualmente do meio ágar-água, sob microscópio óptico, e examinados individualmente para a verificação da presença de outros esporos. Confirmada a presença de um único conídio, este foi transferido para tubo de ensaio contendo o meio FAAT. Após o desenvolvimento das culturas nos tubos de ensaio, foram adicionados $10 \mathrm{~mL}$ de óleo mineral estéril para preservação das culturas até a necessidade de utilização.

\section{Obtenção da massa micelial de Colletotrichum graminicola}

Para a obtenção de massa micelial de $C$. graminicola, foram utilizados 95 isolados monospóricos provenientes dos estados de Goiás, Minas Gerais, Paraná, Rio Grande do Sul, Santa Catarina e São Paulo. Os isolados foram transferidos para placas de Petri contendo meio FAAT e mantidos a 25 ${ }^{\circ} \mathrm{C}$ por 7 dias. Fragmentos de micélio foram transferidos para Erlenmeyers contendo $100 \mathrm{~mL}$ de meio líquido YES (10 g/L de sacarose, $6 \mathrm{~g} / \mathrm{L}$ de extrato de levedura e $6 \mathrm{~g} / \mathrm{L}$ de caseína) previamente esterilizado, adicionado de $1 \mathrm{~mL}$ dos antibióticos streptomicina e tetraciclina $(0,300 \mathrm{mg} / \mathrm{mL})$. Os frascos foram mantidos em agitador a $90 \mathrm{rpm}$ a $28^{\circ} \mathrm{C}$ por $72 \mathrm{~h}$. A massa micelial foi filtrada em duas camadas de gaze esterilizada e, em seguida, em papel de filtro esterilizado. As amostras foram armazenadas em freezer a $-20{ }^{\circ} \mathrm{C}$, envoltas por papel alumínio até o momento da extração do DNA. 


\section{Extração do DNA genômico}

Utilizou-se a metodologia de extração de DNA descrita por Saghai-Maroof et al. (1984), modificada. As amostras foram maceradas em nitrogênio líquido até obtenção de um pó fino e adicionados $350 \mu \mathrm{L}$ de tampão CTAB [2\% (m/v) CTAB; 0,2 M Tris- $\mathrm{HCl}$ $(\mathrm{pH} 7,5) ; 1,4 \mathrm{M} \mathrm{NaCl} ; 0,02 \mathrm{M}$ EDTA (pH 8,0); $2 \%$ (v/v) 2-mercaptoetanol]. A mistura foi mantida em banho maria a $65^{\circ} \mathrm{C}$ durante $1 \mathrm{~h}$. Após resfriamento por 5 min em condição ambiente $\left(25^{\circ} \mathrm{C}\right)$, promoveuse a lavagem com igual volume de solução de clorofórmio-octanol $(24: 1 \mathrm{v} / \mathrm{v})$, com homogeneização constante por $20 \mathrm{~min}$. O material foi centrifugado a $14.000 \mathrm{rpm}$ por $10 \mathrm{~min}$ e o sobrenadante transferido para novo microtubo, onde foram adicionados $300 \mu \mathrm{L}$ de isopropanol mantido a $-20^{\circ} \mathrm{C}$ por, no mínino, $1 \mathrm{~h}$. Os microtubos foram levados à centrífuga e o material contido neles centrifugado a $14.000 \mathrm{rpm}$ por $10 \mathrm{~min}$, o sobrenadante descartado e o precipitado lavado com $140 \mu \mathrm{L}$ de etanol 70\% (v/v) gelado. Os tubos foram novamente levados à centrífuga por $10 \mathrm{~min}$ a uma rotação de $14.000 \mathrm{rpm}$. O sobrenadante foi descartado e o etanol residual seco em estufa a $65^{\circ} \mathrm{C}$ por $5 \mathrm{~min}$. Os DNAs precipitados foram ressuspendidos em 50 $\mu \mathrm{L}$ de tampão TE contendo de RNase A (10 mM Tris$\mathrm{HCl} ; 1$ mM EDTA, pH 8,0; 0,1 $\mu \mathrm{g} / \mu \mathrm{L}$ RNase A). A concentração das amostras foi quantificada em espectrofotômetro Nanodrop e ajustada para $10 \mathrm{ng} / \mu \mathrm{L}$, diluindo-se o DNA estoque em água ultrapura. O DNA foi armazenado a $-20{ }^{\circ} \mathrm{C}$ para posterior utilização.

\section{Amplificação do DNA}

Foi realizada uma pré-seleção dos primers, primeiramente utilizando 16 primers ISSR: AAC, GACA, CGA, ACA, CCA, GT, CAC, ACTG, GTG,
GCGT, CTCGC, AGTC, GAGG, GAAT, AAG e TGGT, sendo escolhidos os nove que resultaram em um maior polimorfismo: AAC, GACA, ACA, GT, ACTG, CTCGC, GAGG, GAAT e AAG. As reações de amplificação via PCR continham um volume final de $20 \mu \mathrm{L}$, consistindo de $3 \mu \mathrm{L}$ de DNA $(10 \mathrm{ng} / \mu \mathrm{L}) ; 20$ $\mathrm{mM}$ Tris- $\mathrm{HCl}\left(\mathrm{pH} \mathrm{8,4);} 50 \mathrm{mM} \mathrm{KCl} ; 2 \mathrm{mM} \mathrm{MgCl}_{2} ; 1\right.$ $\mathrm{U}$ Taq DNA polimerase (Invitrogen, Carslbad, CA), $0,125 \mathrm{mM}$ dNTPs e $0,5 \mu \mathrm{M}$ de cada primer. Os ciclos de amplificação foram: $94{ }^{\circ} \mathrm{C}$ por $2 \mathrm{~min}, 94^{\circ} \mathrm{C}$ por 1 min, $45^{\circ} \mathrm{C}$ por um min, $72{ }^{\circ} \mathrm{C}$ por dois min. Sendo este último ciclo repetido 35 vezes, seguido por um ciclo de $72{ }^{\circ} \mathrm{C}$ por $10 \mathrm{~min}$, mantendo as reações a 10 ${ }^{\circ} \mathrm{C}$ até a retirada da amostra. Todas as amplificações foram realizadas em termociclador Applied Biossystems - PCR System 9700. Às reações, foram adicionados $4 \mu \mathrm{L}$ de corante, sendo essas submetidas à eletroforese em gel de agarose a $1,5 \%(\mathrm{~m} / \mathrm{v})$ a $100 \mathrm{~V}$, em tampão TAE (40 mM Tris-acetato; 1 mM EDTA, pH $8,0)$. Em seguida, o gel foi incubado em solução de brometo de etídio $(1 \mu \mathrm{g} / \mathrm{mL})$ por $20 \mathrm{~min}$, descorado em água por $5 \mathrm{~min}$, visualizado sob luz ultravioleta e fotografado no equipamento Kodak - Gel logic 200.

\section{Análise dos dados}

Os fragmentos de DNA foram avaliados mediante inspeção visual dos géis. Bandas de mesmo peso molecular, em indivíduos diferentes, foram consideradas idênticas e designadas em função da ausência (0) e da presença (1) no gel. Os dados foram analisados empregando o método UPGMA (Unweighted Pair Group Method with Arithmetic mean) utilizando três coeficientes: Dice, Jaccard e Pearson. A matriz de dissimilaridade e o coeficiente de correlação cofenética foram feitos através do site http://genomes.urv. es/UPGMA/ (Garcia-Vallve et al., 1999); a matriz foi 
utilizada para a confecção do dendrograma no programa Statistica 7.

\section{Resultados e Discussão}

Neste trabalho, foi obtida uma coleção de 95 isolados monospóricos de C. graminicola, devidamente identificados (Tabela 1). Nove loci ISSR foram utilizados para caracterizar 144 isolados. Foram identificadas um total de 66 bandas polimórficas, com média de 49 bandas amplificadas por isolado. O loco que obteve o maior número de bandas amplificadas foi o primer GT, com 15 bandas, e o primer com menor número foi GACA, com três bandas, sendo a média de 7,33 bandas por primer.

As matrizes geradas obtiveram os seguintes coeficientes de correlação cofenética: Dicer 0,18 , Jaccard 0,80 e Pearson 0,08 . O coeficiente de correlação cofenética estima o quanto o dendrograma está adequado às interações entre os acessos. $\mathrm{O}$ valor 1 significa que a relação entre os dados e o dendrograma é perfeita (May, 1999). Romesburg (1984) considerou em seu trabalho que valores maiores ou iguais a 0,8 são satisfatórios. Vaz Patto et al. (2004) abordam que valores acima de 0,56 representam um bom alinhamento entre as matrizes de dissimilaridade e agrupamento, de maneira que a matriz escolhida foi a feita com o coeficiente de Jaccard.

Ao analisar o dendrograma, foi considerada a linha divisória no valor da distância genética de 0,3 dividindo os isolados em sete grupos; dos 95 isolados, seis não agruparam (Figura 1). Baseado na análise dos dados, não foi encontrada estruturação geográfica entre os isolados;

o mesmo ocorreu em relação à parte da planta utilizada no isolamento de C. graminicola: colmo (C), folha $(\mathrm{F})$ e nervura $(\mathrm{N})$. Alguns isolados mais antigos não possuíam esta informação, sendo denominados indeterminados (?) (Tabela 1). O primeiro grupo agregou 75 isolados pertencentes aos estados de GO, MG, PR, $\mathrm{RS}, \mathrm{SC}$ e SP; o segundo grupo quatro isolados do PR; o terceiro grupo dois isolados de SC e PR; o quarto grupo dois isolados, um de MG outro do PR; os demais grupos (5, 6 e 7) dois isolados do PR. Os isolados com maior similaridade foram os isolados 44-07 e 46-07, com distância genética de 0,019, sendo os dois isolados da cidade de Passo Fundo (RS).

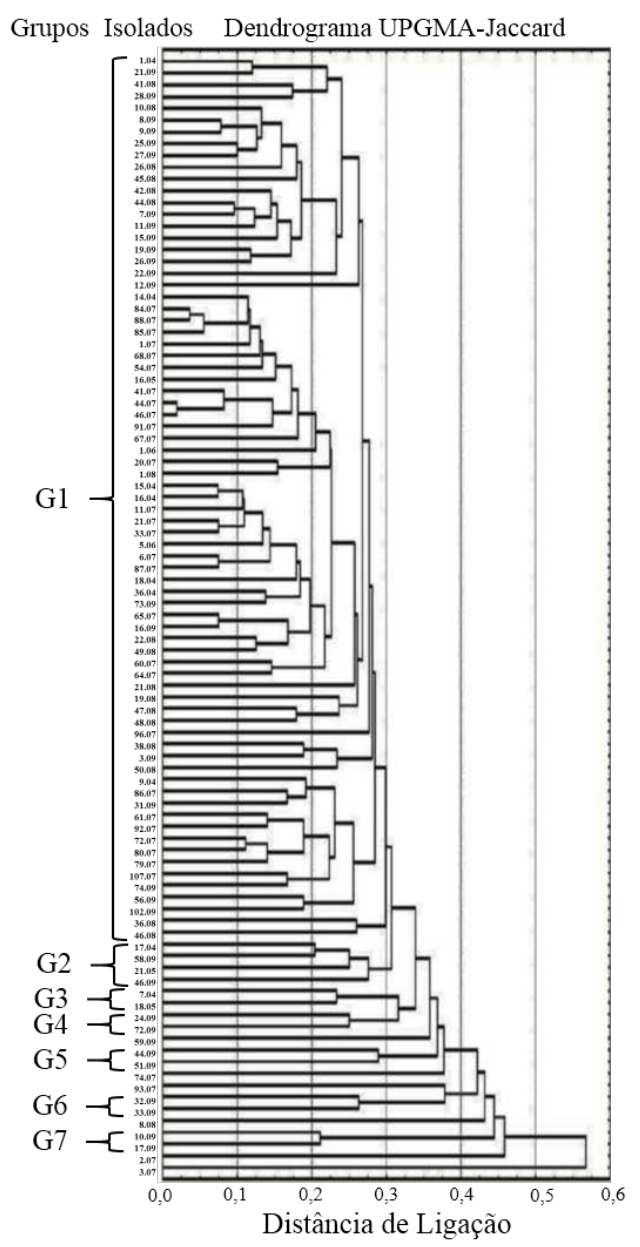

Figura 1. Dendrograma gerado pelo método UPGMA, utilizando 66 bandas amplificadas pelos nove primers ISSR, detectadas em 95 isolados monospóricos de Colletotrichum graminicola. 
Tabela 1. Relação dos isolados utilizados no trabalho seguindo a ordem presente no dendrograma pelo método UPGMA (eixo y) de cima para baixo, com descrição do número do isolado, da parte da planta utilizada para o isolamento (folha-F, colmo-C, nervura-N e indeterminado-?), do local de coleta (estado e cidade) e a qual grupo o isolado foi classificado (baseado no agrupamento UPGMA, utilizando o coeficiente de Jaccard).

\begin{tabular}{|c|c|c|c|c|c|c|c|c|c|}
\hline UPGMA & Cidade & Isolado & Parte & Grupo & UPGMA & Cidade & Isolado & Parte & Grupo \\
\hline 1 & Cristalina-GO & 1.04 & $?$ & 1 & 49 & Campo Mourão-PR & 16.09 & $\mathrm{~F}$ & 1 \\
\hline 2 & Campo Mourão-PR & 21.09 & $\mathrm{~F}$ & 1 & 50 & Sete Lagoas-MG & 22.08 & $\mathrm{~F}$ & 1 \\
\hline 3 & Sete Lagoas-MG & 41.08 & $\mathrm{~F}$ & 1 & 51 & Sete Lagoas-MG & 49.08 & $\mathrm{~F}$ & 1 \\
\hline 4 & Campo Mourão-PR & 28.09 & $\mathrm{~F}$ & 1 & 52 & Goianésia-GO & 60.07 & $?$ & 1 \\
\hline 5 & Sete Lagoas-MG & 10.08 & $\mathrm{~F}$ & 1 & 53 & Sete Lagoas-MG & 64.07 & $\mathrm{C}$ & 1 \\
\hline 6 & Londrina-PR & 8.09 & $\mathrm{~F}$ & 1 & 54 & Sete Lagoas-MG & 21.08 & $\mathrm{~F}$ & 1 \\
\hline 7 & Londrina-PR & 9.09 & $\mathrm{~F}$ & 1 & 55 & Sete Lagoas-MG & 19.08 & $\mathrm{~F}$ & 1 \\
\hline 8 & Campo Mourão-PR & 25.09 & $\mathrm{~F}$ & 1 & 56 & Sete Lagoas-MG & 47.08 & $\mathrm{~F}$ & 1 \\
\hline 9 & Campo Mourão-PR & 27.09 & $\mathrm{~F}$ & 1 & 57 & Sete Lagoas-MG & 48.08 & $\mathrm{~F}$ & 1 \\
\hline 10 & Sete Lagoas-MG & 26.08 & $\mathrm{~F}$ & 1 & 58 & Xapecó-SC & 96.07 & $\mathrm{~F}$ & 1 \\
\hline 11 & Sete Lagoas-MG & 45.08 & $\mathrm{~F}$ & 1 & 59 & Sete Lagoas-MG & 38.08 & $\mathrm{~F}$ & 1 \\
\hline 12 & Sete Lagoas-MG & 42.08 & $\mathrm{~F}$ & 1 & 60 & Sete Lagoas-MG & 3.09 & $\mathrm{~F}$ & 1 \\
\hline 13 & Sete Lagoas-MG & 44.08 & $\mathrm{~F}$ & 1 & 61 & Sete Lagoas-MG & 50.08 & $\mathrm{~F}$ & 1 \\
\hline 14 & Londrina-PR & 7.09 & $\mathrm{~F}$ & 1 & 62 & Xanxerê-SC & 9.04 & $?$ & 1 \\
\hline 15 & Londrina-PR & 11.09 & $\mathrm{~F}$ & 1 & 63 & Sete Lagoas-MG & 86.07 & $\mathrm{C}$ & 1 \\
\hline 16 & Campo Mourão-PR & 15.09 & $\mathrm{~F}$ & 1 & 64 & Campo Mourão-PR & 31.09 & $\mathrm{~F}$ & 1 \\
\hline 17 & Campo Mourão-PR & 19.09 & $\mathrm{~F}$ & 1 & 65 & Sete Lagoas-MG & 61.07 & $\mathrm{C}$ & 1 \\
\hline 18 & Campo Mourão-PR & 26.09 & $\mathrm{~F}$ & 1 & 66 & Xapecó-SC & 92.07 & $\mathrm{C}$ & 1 \\
\hline 19 & Campo Mourão-PR & 22.09 & $\mathrm{~F}$ & 1 & 67 & Sete Lagoas-MG & 72.07 & $\mathrm{C}$ & 1 \\
\hline 20 & Campo Mourão-PR & 12.09 & $\mathrm{~F}$ & 1 & 68 & Sete Lagoas-MG & 80.07 & $\mathrm{C}$ & 1 \\
\hline 21 & Xanxerê-SC & 14.04 & $?$ & 1 & 69 & Sete Lagoas-MG & 79.07 & $\mathrm{C}$ & 1 \\
\hline 22 & Sete Lagoas-MG & 84.07 & $\mathrm{C}$ & 1 & 70 & Iraí-MG & 107.07 & $\mathrm{C}$ & 1 \\
\hline 23 & Sete Lagoas-MG & 88.07 & $\mathrm{C}$ & 1 & 71 & S. S. do Paraiso-MG & 74.09 & $\mathrm{~N}$ & 1 \\
\hline 24 & Sete Lagoas-MG & 85.07 & $\mathrm{C}$ & 1 & 72 & Ponta Grossa-PR & 56.09 & $\mathrm{~F}$ & 1 \\
\hline 25 & Uberaba-MG & 1.07 & $\mathrm{~N}$ & 1 & 73 & Indianápolis-MG & 102.09 & $\mathrm{~N}$ & 1 \\
\hline 26 & Sete Lagoas-MG & 68.07 & $\mathrm{C}$ & 1 & 74 & Sete Lagoas-MG & 36.08 & $\mathrm{~F}$ & 1 \\
\hline 27 & Goianésia-GO & 54.07 & $?$ & 1 & 75 & Sete Lagoas-MG & 46.08 & $\mathrm{~F}$ & 1 \\
\hline 28 & Campo Mourão-PR & 16.05 & $?$ & 1 & 76 & Londrina-PR & 17.04 & $?$ & 2 \\
\hline 29 & Passo Fundo-RS & 41.07 & $?$ & 1 & 77 & Ponta Grossa-PR & 58.09 & $\mathrm{~F}$ & 2 \\
\hline 30 & Passo Fundo-RS & 44.07 & $?$ & 1 & 78 & Londrina-PR & 21.05 & $?$ & 2 \\
\hline 31 & Passo Fundo-RS & 46.07 & $?$ & 1 & 79 & Cascavel-PR & 46.09 & $\mathrm{~F}$ & 2 \\
\hline 32 & Xapecó-SC & 91.07 & $\mathrm{C}$ & 1 & 80 & Xanxerê-SC & 7.04 & $?$ & 3 \\
\hline 33 & Sete Lagoas-MG & 67.07 & $\mathrm{C}$ & 1 & 81 & Campo Mourão-PR & 18.05 & $?$ & 3 \\
\hline 34 & Londrina-PR & 1.06 & $?$ & 1 & 82 & Campo Mourão-PR & 24.09 & $\mathrm{~F}$ & 4 \\
\hline 35 & Sete Lagoas-MG & 20.07 & $?$ & 1 & 83 & S. S. do Paraiso-MG & 72.09 & $\mathrm{~N}$ & 4 \\
\hline 36 & Sete Lagoas-MG & 1.08 & $\mathrm{C}$ & 1 & 84 & Ponta Grossa-PR & 59.09 & $\mathrm{~F}$ & - \\
\hline 37 & Londrina-PR & 15.04 & $?$ & 1 & 85 & Campo Mourão-PR & 44.09 & $\mathrm{~F}$ & 5 \\
\hline 38 & Londrina-PR & 16.04 & $?$ & 1 & 86 & Cascavel-PR & 51.09 & $\mathrm{C}$ & 5 \\
\hline 39 & Sete Lagoas-MG & 11.07 & $\mathrm{C}$ & 1 & 87 & Sete Lagoas-MG & 74.07 & $\mathrm{C}$ & - \\
\hline 40 & Uberlândia-MG & 21.07 & $\mathrm{~N}$ & 1 & 88 & Xapecó-SC & 93.07 & $\mathrm{C}$ & - \\
\hline 41 & Campo Mourão-PR & 33.07 & $?$ & 1 & 89 & Campo Mourão-PR & 32.09 & $\mathrm{~F}$ & 6 \\
\hline 42 & Uberlândia-MG & 5.06 & $?$ & 1 & 90 & Campo Mourão-PR & 33.09 & $\mathrm{~F}$ & 6 \\
\hline 43 & Uberaba-MG & 6.07 & $\mathrm{~F}$ & 1 & 91 & Sete Lagoas-MG & 8.08 & $\mathrm{~F}$ & - \\
\hline 44 & Sete Lagoas-MG & 87.07 & $\mathrm{C}$ & 1 & 92 & Londrina-PR & 10.09 & $\mathrm{~F}$ & 7 \\
\hline 45 & Campo Mourão-PR & 18.04 & $?$ & 1 & 93 & Campo Mourão-PR & 17.09 & $\mathrm{~F}$ & 7 \\
\hline 46 & Colombia-SP & 36.04 & $?$ & 1 & 94 & Uberaba-MG & 2.07 & $\mathrm{~F}$ & - \\
\hline 47 & S. S. do Paraiso-MG & 73.09 & $\mathrm{~N}$ & 1 & 95 & Cristalina-GO & 3.07 & $\mathrm{~F}$ & - \\
\hline 48 & Sete Lagoas-MG & 65.07 & $\mathrm{C}$ & 1 & - & - & - & - & - \\
\hline
\end{tabular}


Um dos primeiros trabalhos feitos com diversidade de C. graminicola foi realizado por Forgey et al. (1978) utilizando dez isolados e dez progênies de milho que, baseados nos resultados do teste de inoculação cruzada onde cada um dos isolados foi inoculado nas dez progênies de milho, propuseram a ocorrência de oito raças fisiológicas. Posteriormente, Nicholson \& Warren (1981), utilizando sete dos dez isolados empregados no trabalho de Forgey et al. (1978), contestaram a presença de raças, atribuindo a diferença quanto à sintomatologia ao fato dos autores não terem padronizado as inoculações no experimento. Segundo Bergstrom \& Nicholsom (1999), existe uma grande variabilidade quanto à agressividade da antracnose em folhas e em colmo de milho. Outra maneira de verificar a variabilidade de um organismo pode ser obtida com o uso de marcadores moleculares, diferenciando os indivíduos baseado no seu material genético. Ratanacherdchai et al. (2010) trabalharam com variabilidade de C. gloeosporioides e C. capsici com três genótipos de pimenta utilizando marcadores ISSR. O dendrograma obtido correlacionou os isolados quanto à sua origem geográfica, propondo assim o uso de marcadores ISSR no estudo da diversidade genética em Colletotrichum spp, afirmando ainda que tais técnicas ajudam no estudo da dinâmica populacional do patógeno, permitindo estratégias de controle com uma melhor eficiência.

Neste trabalho, foi encontrada uma grande variabilidade entre os isolados, corroborando com as inferências sobre a grande variabilidade de C. graminicola proposta por Bergstrom \& Nicholson (1999). A variabilidade genética é uma condição presente em patossistemas silvestres preservados e é aumentada em agroecossistemas. A alteração dos cultivos por meio do melhoramento, a ampliação de fronteiras agrícolas e o uso desmedido de defensivos sistêmicos são fatores que aumentam a força da seleção exercida sobre as populações de patógenos. Todos estes fatores favorecem novos genes de virulência e o polimorfismo na estrutura dessas populações (Araya, 2003). Em 2008, um gene que codifica para uma proteína de resistência a antracnose do colmo foi clonado (Broglie et al., 2006). O simples uso desse gene nos futuros híbridos pode exercer uma pressão direcional sobre a população do patógeno, rumo ao surgimento de novos patótipos (Casela \& Guimarães, 2005).

\section{Conclusões}

1- A variabilidade genética entre os isolados de C. graminicola é alta.

2- Marcadores ISSR são eficientes na determinação da variabilidade de C. graminicola.

3- Os isolados de C. graminicola utilizados no presente trabalho não apresentam estruturação geográfica no Brasil.

4- Os isolados de C. graminicola utilizados no presente trabalho não apresentam estruturação em relação à parte da planta utilizada na obtenção do isolado.

\section{Agradecimentos}

Os autores agradecem à Coordenação de Aperfeiçoamento de Nível Superior (Capes), ao Conselho Nacional de Desenvolvimento Cientifico e Teológico (CNPq), à Fundação de Amparo à Pesquisa do Estado de Minas Gerais (Fapemig) e à Embrapa Milho e Sorgo pelo suporte financeiro.

\section{Referências}

ARAYA, C. M. Coevolución de interacciones hospedante-patógeno en frijol común. Fitopatologia Brasileira, Brasília, DF, v. 28, n. 3, p. 221-228, 2003.

DOI: $10.1590 / \mathrm{S} 0100-41582003000300001$.

BERGSTROM, G. C.; NICHOLSON, R. L. The biology of corn anthracnose: knowledge to exploit for improved mana- 
gement.PlantDisease, SaintPaul,v.83,n.7,p.596-608, 1999. DOI: 10.1094/PDIS.1999.83.7.596.

BIDARTONDO, M. I. Preserving accuracy in GenBank. Science, Washington, v. 319, n. 5870, p. 1616a, 2008. DOI: $10.1126 /$ science.319.5870.1616a.

BORNET, B.; BRANCHARD, M. Non anchored Inter Simple Sequence Repeat (ISSR) markers: reproducible and specific tools for genome fingerprinting. Plant Molecular Biology Reporter, Athens, v. 19, p. 209-215, 2001. DOI: $10.1007 / \mathrm{BF} 02772892$.

BROGLIE, K. E.; BUTLER, K. H.; BUTRUILLE, M. G.; CONCEICAO, A. da S.; FREY, T. J.; HAWK, J. A.; JAQUETH, J. S.; JONES, E. S.; MULTANI, D. S.; WOLTERS, P. J. C. C. Polynucleotides and methods for making plants resistant to fungal pathogens. PCT/ US2006/012443. WO2006107931 A2. 12 Oct. 2006, 4 Apr. 2006. Patent.

CAI, L.; HYDE, K. D.; TAYLOR, P. W. J.; WEIR, B. S.; WALLER, J.; ABANG, M. M.; ZHANG, J. Z.; YANG, Y. L.; PHOULIVONG, S.; LIU, Z. Y.; PRIHASTUTI, H.; SHIVAS, R. G.; MCKENZIE, E. H. C.; JOHNSTON, P. R. A polyphasic approach for studying Colletotrichum. Fungal Diversity, Chiang Mai, v. 39, p. 183-204, 2009.

CASELA, C. R.; GUIMARÃES, F. B. Rotação de genes no manejo da resistência a doenças. Revisão Anual de Patologia de Plantas, Passo Fundo, v. 13, p. 321-349, 2005.

COTA, L. V.; COSTA, R. V. da; SILVA, D. D.; CASELA, C. R.; PARREIRA, D. F. Quantification of yield losses due to anthracnose stalk rot on corn in Brazilian conditions. Journal of Phytopathology, Berlin, v. 160, n. 11/12, p. 680-684, 2012. DOI: $10.1111 /$ jph.12008.

CROUCH, J. A.; BEIRN, L. A. Anthracnose of cereals and grasses. Fungal Diversity, Chiang Mai, v. 39, p. 19-44, 2009.

CROUCH, J. A.; CLARKE, B. B.; HILlMAN, B. I. Unraveling evolutionary relationships among the divergent lineages of Colletotrichum causing anthracnose disease in turfgrass and corn. Phytopathology, Saint Paul, v. 96, n. 1, p. 46-60, 2006. DOI: 10.1094/PHYTO-96-0046.

CROUCH, J. A.; CLARKE, B. B.; HILLMAN, B. I. What is the value of ITS sequence data in Colletotrichum systematics and species diagnosis? A case study using the falcate-spored, graminicolous Colletotrichum group. Mycologia, New York, v. 101, n. 5, p. 648-656, 2009a.

DOI: $10.3852 / 08-231$.

CROUCH, J. A.; CLARKE, B. B.; WHITE, J. F.; HILLMAN, B. I. Systematic analysis of the falcate-spored graminicolous Colletotrichum and a description of six new species of the fungus from warm season grasses. Mycologia, New York, v. 101, n. 5, p. 717-732, 2009b.

DOI: $10.3852 / 08-230$.

FORGEY, W. M.; BLANCO, M. H.; LOEGERING, W. Q. Differences in pathological capabilities and host specificity of Colletotrichum graminicola on Zea mays. Plant Disease Reporter, Beltsville, v. 62, n. 7, p. 573-576, 1978.

GARCIA-VALlVE, S.; PALAU, J.; ROMEU, A. Horizontal gene transfer in glycosyl hydrolases inferred from códon usage in Escherichia coli and Bacilus subtilis. Molecular Biology and Evolution, v. 16, n. 9, p. 1125-1134, 1999.

HYDE, K. D.; CAI, L.; CANNON, P. F.; CROUCH, J. A.; CROUS, P. W.; DAMM, U.; GOODWIN, P. H.; CHEN, H.; JOHNSTON, P. R.; JONES, E. B. G.; LIU, Z. Y.; MCKENZIE, E. H. C.; MORIWAKI, J.; NOIREUNG, P.; PENNYCOOK, S. R.; PFENNING, L. H.; PRIHASTUTI, H.; SATO, T.; SHIVAS, R. G.; TAN, Y. P.; TAYLOR, P. W. J.; WEIR, B. S.; YANG, Y. L.; ZHANG, J. Z. Colletotrichum - names in current use. Fungal Diversity, Chiang Mai, v. 39, p. 147-182, 2009a.

HYDE, K. D.; CAI, L.; MCKENZIE, E. H. C.; YANG, Y. L.; ZHANG, J. Z.; PRIHASTUTI, H. Colletotrichum: a catalogue of confusion. Fungal Diversity, Chiang Mai, v. 39, p. 1-17, 2009b. 
MAY, A. C. W. Towards more meaningful hierarchical classification of amino acid scoring matrices. Protein Engineering, Washington, v. 12, n. 9, p. 707-712, 1999.

DOI: $10.1093 /$ protein/12.9.707.

NAGAOKA, T.; OGIHARA, Y. Applicability of intersimple sequence repeat polymorphisms in wheat for use as DNA markers in comparison to RFLP and RAPD markers. Theoretical and Applied Genetics, New York, v. 94, n. 5, p. 597-602, 1997.

DOI: $10.1007 / \mathrm{s} 001220050456$.

NGHIA, N. A.; KADIR, J.; SUNDERASAN, E.; ABDULLAH, M. P.; MALIK, A.; NAPIS, S. Morphological and Inter Simple Sequence Repeat (ISSR) markers analyses of Corynespora cassiicola isolates from rubber plantations in Malaysia. Mycopathologia, The Hague, v. 166, n. 4, p. 189-201, 2008.

DOI: $10.1007 / \mathrm{s} 11046-008-9138-8$.

NICHOLSON, R. L.; WARREN, H. L. The issue of races of Colletotrichum graminicola pathogenic to corn. Plant Disease, Saint Paul, v. 65, p. 143-145, 1981.

DOI: 10.1094/PD-65-143.
RATANACHERDCHAI, K.; WANG, H.-K.; LIN, F.-C.; SOYTONG, K. ISSR for comparison of cross-inoculation potential of Colletotrichum capsici causing chilli anthracnose. African Journal of Microbiology Research, v. 4, n. 1, p. 76-83, 2010.

ROMESBURG, H. C. Cluster analysis for researchers. Belmont: Lifetime Learning Publishers, 1984.

SAGHAI-MAROOF, M. A.; SOLIMAN, K. M.; JORGENSEN, R. A.; ALLARD, R. W. Ribosomal DNA spacer-length polymorphisms in barley: mendelian inheritance, chromosomal location, and population dynamics. Proceedings of the National Academy of Sciences of the United States of America, Washington, v. 81, n. 24, p. 8014-8018, 1984. DOI: $10.1073 /$ pnas.81.24.8014.

VAZ PATTO, M. C.; SATOVIC, Z.; PÊGO, S.; FEVEREI$\mathrm{RO}, \mathrm{P}$. Assessing the genetic diversity of Portuguese maize germplasm using microsatellite markers. Euphytica, Wageningen, v. 137, p. 63-72, 2004.

DOI: 10.1023/B:EUPH.0000040503.48448.97. 